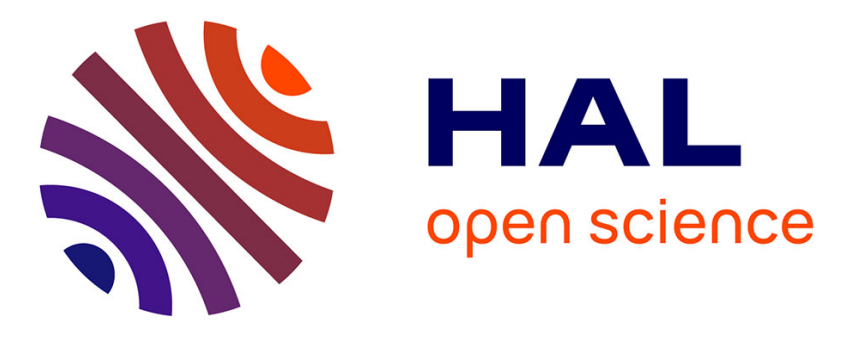

\title{
Aortic dilatation: Value of echocardiography in the systematic assessment of elite rugby players in the French National Rugby League (LNR)
}

Laurent Chevalier, Luc Corneloup, Francois Carré, Aude Mignot, Jérémie Jaussaud, Laurent Gencel, Stephanie Clement-Guinaudeau, Thomas Pospiech

\section{To cite this version:}

Laurent Chevalier, Luc Corneloup, Francois Carré, Aude Mignot, Jérémie Jaussaud, et al.. Aortic dilatation: Value of echocardiography in the systematic assessment of elite rugby players in the French National Rugby League (LNR). Scandinavian Journal of Medicine and Science in Sports, 2021, 31 (5), pp.1078-1085. 10.1111/sms.13919 . hal-03128126

\section{HAL Id: hal-03128126 \\ https://hal.science/hal-03128126}

Submitted on 19 Feb 2021

HAL is a multi-disciplinary open access archive for the deposit and dissemination of scientific research documents, whether they are published or not. The documents may come from teaching and research institutions in France or abroad, or from public or private research centers.
L'archive ouverte pluridisciplinaire HAL, est destinée au dépôt et à la diffusion de documents scientifiques de niveau recherche, publiés ou non, émanant des établissements d'enseignement et de recherche français ou étrangers, des laboratoires publics ou privés. 
DR LAURENT CHEVALIER (Orcid ID : 0000-0002-7857-1132)

DR LUC CORNELOUP (Orcid ID : 0000-0003-1951-8195)

DR THOMAS POSPIECH (Orcid ID : 0000-0001-6379-124X)

\author{
Article type : Original Article
}

Aortic dilatation: value of echocardiography in the systematic assessment of elite rugby players in the French National Rugby League (LNR)

Echocardiography in elite rugby players

Chevalier L (1, 2), Corneloup (1), Carré F (3), Mignot A (1), Jaussaud J (1), Gencel L (1), Clement-Guinaudeau S (1), Pospiech T (1).

(1) Clinique du Sport, Bordeaux-Mérignac, France (2) Ligue Nationale Rugby, Paris, France (3) Univ Rennes 1, CHU Rennes, Inserm, LTSI - UMR 1099, F-35000 Rennes, France

Corresponding author: th.pospiech@gmail.com

Acknowledgments: the authors would like to thank Dr Vincent Planche for his contribution to statistical analysis. ABSTRACT

The value of echocardiography in the screening of athletes in addition to the electrocardiogram is debated and still unclear. 336 rugby players in French professional divisions (Top 14, Pro D2) were prospectively assessed with electrocardiogram and echocardiography. 75\% were Caucasian, 16.4\% Pacific Islanders and 8.6\% Afro-Caribbean. Six $(1.8 \%)$ players had electrocardiogram abnormalities, exclusively negative T-waves. Twenty-one (6.25\%) of them had abnormal echocardiography findings: one possible early hypertrophic cardiomyopathy, one anomalous origin of coronary artery, two left ventricular dilatations, one isolated bicuspid aortic valve, two aortic regurgitations and 14 ascending aortic dilatations. The median aortic diameter was modestly correlated with age: $32 \mathrm{~mm}$ [23-48] in players aged $\leq 25$ years vs $33.5 \mathrm{~mm}$ [24-50] in those aged $>25$ years $(\mathrm{p}=0.02$, correlation coefficient -0.01$)$. This tendency increased with cumulative hours of weight training: $34 \mathrm{~mm}$ [24-50] in forwards vs $32 \mathrm{~mm}$ [25-44] in backs ( $\mathrm{p}=0.01)$; and ethnicity, with Pacific Islanders having higher values in both raw data and body surface area or height-indexed data than Afro-Caribbeans and Caucasians: 34 [25-50] vs 32 [27-48] and 33 [23-49] mm (p=0.017); 15 [12.2-21] vs 14.8 [11-19.9] and 14.8 [10-20.9] $\mathrm{mm} / \mathrm{m}^{2}(\mathrm{p}<0.0001) ; 18.5[14-25] \mathrm{mm} / \mathrm{m}$ vs $17.4[14.8-25] \mathrm{mm} / \mathrm{m}$ and 17.6 [12.2$25.3] \mathrm{mm} / \mathrm{m}(\mathrm{p}=0.0125)$. In a population of professional rugby players, echocardiography was contributive. The main anomaly was aortic dilatation (14/336, 4.2\%). While this is proportionally much higher than in other sports, the cutoffs need to be defined more precisely by including the criterion of ethnicity, as is already the case for electrocardiography.

Key words: echocardiography, rugby, pre participation screening, aortic dilatation, ethnicity. 
(c)

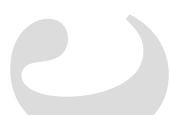

( )

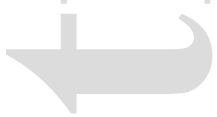

(
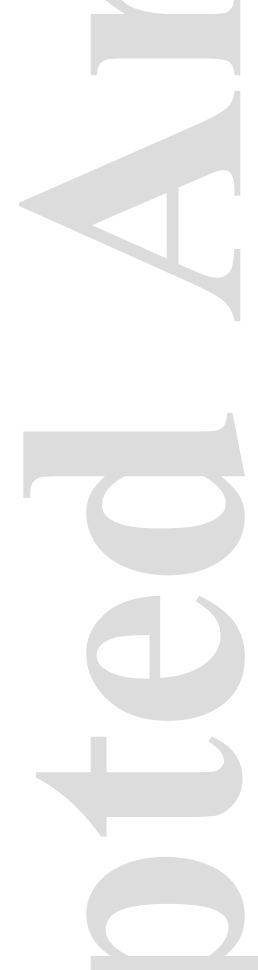

(

P

(

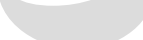

1 


\section{Declarations}

Funding : none

\section{Conflicts of interest: none}

Authors' contribution : Laurent Chevalier, concept/design, data collection, data analysis/interpretation, critical revision of the article, approval of article; Luc Corneloup, data collection, critical revision of the article ,approval of the article; François Carré, concept/design, critical revision of the article, approval of article; Aude Mignot, data collection, critical revision of the article, approval of the article; Jérémie Jaussaud, data collection, critical revision of the article, approval of the article; Laurent Gencel, data collection, critical revision of the article, approval of the article; Stéphanie Clément-Guinaudeau, data collection, critical revision of the article, approval of the article; Thomas Pospiech, data collection, data analysis/interpretation, statistics, critical revision of the article, approval of article. 


\section{INTRODUCTION}

The risk of cardiovascular accidents seems to be increased during the practice of competitive sports, so most countries make pre-participation cardiovascular screening mandatory. However, the protocol to be followed is still under discussion. While the debate on the role of the electrocardiogram (ECG) rages, the contribution of echocardiography (ECHO) is also an unresolved issue. Several studies have sought to clarify the contribution of systematically performing ECHO to screen for cardiovascular pathologies in competitive athletes, with conflicting results on its additional diagnostic value. ${ }^{1-6}$

Several professional leagues and international federations, such as FIFA and World Rugby, require a regular echocardiographic examination in addition to the routine check-up, with interview, physical examination and resting ECG, as recommended since 2005 by the European Society of Cardiology. ${ }^{7}$ Thus, the French National Professional Rugby League has required a resting ECG at regular intervals since 2000 every 4 years, and every 2 years since 2017 .

A recent study on rugby veterans showed a high prevalence of ascending aortic dilatation, thus questioning whether ultrasonography is of sufficient value in this setting and whether there is a causal link between playing rugby and an increased aortic diameter. ${ }^{8-9}$

The aim of this prospective study was to quantify the proportion of aortic abnormalities in a population of young rugby players and to evaluate the potential diagnostic contribution of systematic ECHO in addition to the routine cardiovascular screening recommended by the European Society of Cardiology with respect to the risk of sudden death in elite professional rugby players. 


\section{MATERIAL AND METHODS}

\subsection{Study population}

From June 2015 to September 2019, this monocenter descriptive study prospectively and consecutively included 336 male professional rugby players. All of them played in the French first and second division rugby championships.

\subsection{Experimental procedure}

All athletes were given a pre-evaluation cardiovascular assessment, including interview, physical examination, resting ECG and ECHO. The ECGs were performed on a digital platform (General Electric Healthcare ${ }^{\circledR}$, Chicago, USA) and interpreted according to recent recommendations. ${ }^{10}$ ECHO was recorded with a Vivid 6 unit (General Electric Healthcare ${ }^{\circledR}$, Chicago, USA) as recommended. ${ }^{11}$ Data was analyzed in accordance with the recommendations. ${ }^{11}$ The origin of the coronary ostia was systematically sought. Morphological values (diameter, volume, surface and thickness) of the cavities were indexed to body surface area. Aortic diameter was also indexed to body surface area, size, and $\mathrm{Z}$ score. ${ }^{12} \mathrm{Z}$ score was calculated with the formula: (expected aortic value - observed aortic value) / 0.261. Expected value was calculated using: BSA $2.423+($ age $[$ years] $\times 0.009)+($ BSA [square meters] $\times 0.461)-($ gender $[1=$ man, $2=$ woman $] \times 0.267$ ). Aortic measurements were taken from the $2 \mathrm{D}$ parasternal long axis view, perpendicular to the direction of blood flow, using the leading edge to leading edge convention. Left ventricular ejection fraction was calculated with the Simpson Biplan method.

As in previous research in rugby players, values greater than $65 \mathrm{~mm}$ and $13 \mathrm{~mm}$ for telediastolic diameter and the walls of the left ventricle, respectively, and greater than $40 \mathrm{~mm}$ for the diameter of the aortic root were classified as abnormal. ${ }^{13-16}$ ECG and ECHO data were analyzed by two independent cardiologists. In the event of discrepancies, a new double-reading analysis was performed. The players gave written informed consent for the statistical use of their anonymized medical data. The study was performed in accordance with the ethical standards as laid down in the 1964 Declaration of Helsinki and with approval of the local institutional ethics committee (ethics committee of "Clinique du Sport de Bordeaux-Merignac").

\subsection{Statistical analysis}

The Shapiro-Wilk test and the Kolmogorov-Smirnov test confirmed the non-normal distribution of continuous variables. Numerical values are expressed as mean \pm standard deviation (SD) or median (range) for continuous variables, and number (percentages) for discontinuous variables. Qualitative variables were compared with the Chisquared test. Statistical comparisons with the Student t-test were performed between two age groups (18-25 vs 26-33 years) and between two players groups (backs $v s$ forwards). The potential impact of ethnicity (Caucasian, AfroCaribbean, Pacific Islander) was studied with the Kruskall-Wallis test for non-parametric data and with Dunn's multiple comparison test. The level of significance was set to $p<0.05$. Statistical analysis was conducted using Excel (Microsoft ${ }^{\circledR}$,

Seattle,

USA). 


\section{RESULTS}

Of the 336 rugby players included, 252 (75\%) were Caucasian, 55 (16.4\%) Pacific Islanders, and 29 (8.6\%) AfroCaribbean. Their anthropometric data are presented in Table 1. No symptoms or personal or family history were found during the interview. All physical examinations were normal.

\subsection{Electrocardiogram data}

ECG revealed abnormalities in six (1.8\%) players. These were only negative $\mathrm{T}$ waves (one in inferior leads, one in lateral leads, two in inferior-lateral leads and two in inferior + septo-apico-lateral leads). In two cases, ECHO was abnormal. In the first who had possible early hypertrophic cardiomyopathy, the abnormal finding explained the repolarization disorder; in the second, the bicuspid aortic valve with aortic dilatation did not explain it. In the other four cases, the recommended imaging, exercise exploration and Holter ${ }^{14}$ did not reveal any detectable pathology. Of the five players with unexplained repolarization disorders, four received annual cardiologic follow-up for two years, which proved normal. The last player was lost to follow-up after the first assessment.

\subsection{Echographic data}

The cardiac morphological parameters of the population are shown in Table 2. Abnormalities were observed in 21 players (Table 3) and were not accompanied by ECG abnormalities in 19 of them. Two patients showed dilatation of the left ventricle $>65 \mathrm{~mm}$, a possible early hypertrophic cardiomyopathy (infero-lateral wall of left ventricle thickness at $13 \mathrm{~mm}$, no arrhythmia on stress test or on stress ECG Holter, asymmetry thickness confirmed on MRI but without fibrosis, no family history) and a benign form of anomalous origin of the right coronary artery (no stress symptoms, no arrhythmia or ischemia on the stress test, no intramural pathway, no acute angulation at the ostium exit or any aortic-pulmonary pathway). In 17 cases (81\% of abnormal ECHO), the abnormalities concerned the aorta and the aortic valve. One player had an isolated benign bicuspid aortic valve and two players had minor aortic regurgitation, one of which was associated with minor mitral regurgitation. Fourteen players had aortic dilatation: 13 had aortic dilatation in the sinus and one in the sinus and tube, of whom only one had a bicuspid aortic valve with associated aortic regurgitation, and 13 had a tricuspid aortic valve. The characteristics of the dilatations and the players are shown in Table 4. The mean value of ascending aorta for the 336 players after correction for BSA is $15 \pm 3 \mathrm{~mm} / \mathrm{m}^{2}$. On the fourteen players with value $>40 \mathrm{~mm}$, only two have value $\leq 16 \mathrm{~mm} / \mathrm{m}^{2}$ and these ones have Z-Score $<2$. There are two other players with aorta $<40 \mathrm{~mm}$ but with Z-Score $>2$. Moreover, among the 336 players, 69 have value $>16 \mathrm{~mm} / \mathrm{m}^{2}$, $23>17 \mathrm{~mm} / \mathrm{m}^{2}, 11>18 \mathrm{~mm} / \mathrm{m}^{2}$ and $8>19 \mathrm{~mm} / \mathrm{m}^{2}$. All abnormal ECHO measurements, parietal hypertrophy, bicuspid valvular anomalies, coronary pathway abnormalities and aortic dilatations were confirmed by sectional imaging (MRI and/or CT). 


\section{DISCUSSION}

In total, cardiovascular work-up revealed abnormalities in 25 (7.4\%) of 336 elite rugby players. All abnormalities were revealed by ECG $(n=6)$ or ECHO $(n=21)$ and rarely $(n=2)$ by both examinations. A targeted and exhaustive complementary cardiovascular check-up (exercise test, Holter ECG, cardiac MRI, Cardiac Tomography) was performed for each of the players concerned with, when justified, a shared decision of collegial expert panel regarding the continuation of the sport at competitive level. Except for a 20 -year-old player with a rapidly increasing $48-\mathrm{mm}$ aortic dilatation for whom a career as a professional athlete seemed unreasonable, all the players were allowed to continue competitive rugby with regular cardiological follow-up (older players, already professional, with stability of dilatation on successive echos or CT/MRI). With a mean follow-up of $32 \pm 23$ months, none of the players with a $Z$ score $>3$ presented a dissection despite playing elite professional rugby.

\subsection{Contribution of ECG}

Resting ECG was abnormal in only six (1.8\%) out of 336 players and revealed only negative $\mathrm{T}$ waves. Five of the six players received complementary MRI, the other refusing any further examination. None of them had any subendocardial or subepicardial fibrosis. Only one had an aspect of hypertrophic, localized, minor heart disease, with ECG abnormalities that had been absent two years earlier. Of the remaining five, two were Pacific Islanders (diffuse ECG abnormalities), two Afro-Caribbean (inferior and inferior-lateral ECG abnormalities) and one Caucasian (inferior-lateral ECG abnormalities). Abnormalities remained stable at two years in four of them, and the other was lost to follow-up. This low prevalence of ECG abnormalities may be explained by the fact that most of the players had had several resting ECGs since entering the training center.

\subsection{Contribution of ECHO}

The mean heart morphologic values in our players are similar to those found in recent series of elite rugby or American football players. ${ }^{14,18-21}$ On the other hand, the prevalence of echocardiographic abnormalities in our subjects is significantly higher than that reported in previous studies, which did not include rugby players. ${ }^{1-5}$ Regarding valvulopathies and large left ventricular dilatations, the presence of two cases of bicuspid aortic valve is consistent with the reported prevalence in the general population. ${ }^{22}$ The two players with a ventricular dilatation $>65 \mathrm{~mm}$ and otherwise normal values will continue to receive regular cardiologic monitoring, as recommended. ${ }^{13}$ The abnormalities observed mainly concerned the aorta (81\%), and it was aortic dilatation which almost always involved the Valsalva sinuses in $56 \%$ of these cases. Aortic dilatation was diagnosed when the diameter of the aorta exceeded $40 \mathrm{~mm}$, as recommended. ${ }^{13}$ Thus, an aortic diameter greater than $40 \mathrm{~mm}$ was observed in $4.2 \%$ of our rugby players.

The number of cases of dilated aorta deserves attention, regardless of the assessment method used (absolute value, indexing to body surface area, indexing to size, $\mathrm{Z}$ score). This is in line with the findings of Kay in elite rugby players, most of whom were retired. ${ }^{8}$ Several explanations can be proposed. First, our population is older than other cohorts ${ }^{1-4}$ and has more years of elite practice, which is likely to generate ultrasound modifications, particularly aortic, as highlighted by Pelliccia ${ }^{15}$ and Gentry. ${ }^{29}$ However, other studies on comparable populations did not demonstrate a clear link between practicing sport and an increased aortic diameter, as in cases of bicuspid aortic valve. ${ }^{22-24}$ In our population, the impact of age on aortic diameter was statistically significant, with higher values in the group $>25$ years 
than in the 18-25 age group (Table 5). Kay et $\mathrm{al}^{8}$ also found that the number of years of competition was a differentiating factor for aortic diameter. We considered two age groups based on the median age of our players, i.e. 25 years. This increase in aortic diameter with years of practice underlines the contribution of ECHO and in particular the importance of repeating it over time, since a player can have an ascending aorta at $35 \mathrm{~mm}$ at 18 years of age and $45 \mathrm{~mm}$ at 30 years of age. However, the mean values observed are well below the threshold values considered pathological. Therefore, age does not seem to be the most important factor in explaining our observations.

Second, the type of effort involved in rugby may play a role. Activities involving high resistance may potentially promote aortic root dilation. ${ }^{25,26}$ Intensive heavy weight training (at least $4 \mathrm{~h} /$ week) in our rugby players could therefore have an impact on the risk of aortic dilatation. Moreover, the forwards lift heavier weights do an additional $1 \mathrm{~h} /$ week of isometric weight training with scrum work, i.e. $+25 \%$, which could partially explain the large percentage of these players with aortic dilatation (71\%), as well as the difference in prevalence between the forwards $(10 / 180$, i.e. $5.5 \%)$ and the backs $(4 / 156$, i.e. $2.6 \%, \mathrm{p}=0.02)$. Overall, these two factors have an additive potentiating effect since among the five players with an aortic diameter $>44 \mathrm{~mm}$, four were aged 25, 28, 30 and 35, and four were forwards.

A third hypothesis concerns ethnicity. Our sample comprised 16\% of Pacific Islanders and 9\% of Afro-Caribbeans,

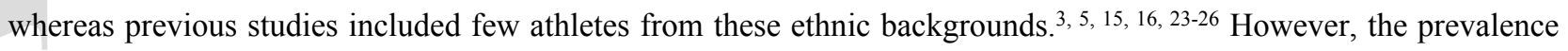
of dilated aorta was significantly higher in a sports population of similar size and with a high Afro-Caribbean component. ${ }^{29}$ The only study on the heart of Pacific rugby players to date ${ }^{18}$ did not focus on the aorta. In our cohort, the median aortic diameter of Pacific Islanders, expressed as both raw and indexed values, was statistically higher than in the other two ethnic groups (Table 5). Furthermore, only one of the five players with significant dilatation of $>$ $44 \mathrm{~mm}$ is Caucasian.

While our results are consistent with those of Kay et $\mathrm{l}^{8}$ with a higher rate of aortic dilatation than in other sports, our prevalence remains significantly lower. Fourteen players had an aortic root $>40 \mathrm{~mm}$, i.e. $4 \%$ of our sample vs. $41 \%$ $(\mathrm{p}<0.001)$ in Kay's Australian study. The same is true for our percentage of Valsalva sinus with Z score $>2(3.6 \%$ vs $24 \%, \mathrm{p}<0.001)$ and with $\mathrm{Z}$ score $>3(1.5 \%$ vs $4 \%$, p: 0.15$)$. On the other hand, only one player $(0.3 \%$ vs $53 \%$, $\mathrm{p}<0.001$ ) had a $\mathrm{Z}$ score $>2$ in the ascending aorta. As the average age of our sample was much lower than in Kay's $(24 \pm 5$ vs $45 \pm 13$ years, $\mathrm{p}<0.0001)$, it is tempting to speculate that our players will in the future have aortic dilatation values similar to those found in Kay's series, and that the ascending aorta will prove to be the Achilles heel of elite rugby players in the long term in terms of cardio-vascularity. In any case, the results of these two studies plead for regular long-term monitoring by ECHO and long-axis imaging.

\section{PERSPECTIVES}

The present findings seem to argue for performing an echocardiographic examination in addition to resting ECG before allowing rugby players to undertake intensive competition. Studies conducted on other populations have not reached the same conclusions. Although we were unable to establish whether ECHO can reveal the potential causes of sudden death in rugby players, the anomalous origin of the coronary artery, bicuspid aortic valve and dilatation of the ascending aorta are abnormalities that cannot be detected by physical examination or ECG, and their significant prevalence would seem to justify systematically performing ECHO at least once before the age of 20 years. However, the type of physical activity undertaken, the duration of practice and ethnicity also have an impact on some of the 
findings. Apart from the issue of adding ECHO or not, it seems fundamental to define cutoffs specific to each type of sport, with weightings for cumulative hours performed, type of endurance or resistance activity and for ethnicity, as with resting ECG, in order to be able to judge whether the values found in elite athletes are within the normal range for a given sport.

\section{CONCLUSION}

In this population of elite rugby players, ECHO was particularly useful in detecting aortic dilatation. Although it was relatively uninformative regarding ECG abnormalities in five of the six T-wave-negative players, 20 of the 25 players with an abnormal screening test were nevertheless screened using ECHO alone. It therefore seems necessary to study each type of professional sport in greater detail before deciding whether systematic ECHO is useful. It is certainly of value in rugby in view of the significant prevalence of dilatations of the ascending aorta. Our findings also raise the question of the threshold aortic values for allowing the continuation of competitive professional sport in an ethnically diverse population subject to major isometric loading from the end of adolescence and in whom no aortic dissection either during training or in matches has been diagnosed or reported in the records of the LNR these last twenty years. 


\section{REFERENCES}

1. Gleason CN, Kerkhof DL, Cilia EA et al. Early screening for cardiovascular abnormalities with preparticipation echocardiography: feasibility study. Clin J Sport Med. 2017;27(5):423-429.

2. Anderson JB, Grenier M, Edwards NM et al. Usefulness of combined history, physical examination, electrocardiogram, and limited echocardiogram in screening adolescent athletes for risk for sudden cardiac death. Am J Cardiol. 2014;114(11):1703-7.

3. Grazioli G, Merino B, Montserrat S et al. Usefulness of echocardiography in preparticipation screening of competitive athletes. Rev Esp Cardiol. 2014;67(9):701-5.

4. Yim ES, Basilico F, Corrado G. Early screening for cardiovascular abnormalities with preparticipation echocardiography: utility of focused physician-operated echocardiography in preparticipation screening of athletes. J Ultrasound Med. 2014;33(2):307-13.

5. Riding NR, Sharma S, Salah O et al. Systematic echocardiography is not efficacious when screening an ethnically diverse cohort of athletes in West Asia. Eur J Prev Cardiol. 2015;22:263-70.

6. Orchard JJ, Orchard JW, La Gerche A et al. Cardiac screening of athletes: consensus needed for clinicians on indications for follow-up echocardiography testing. $\mathrm{Br} \mathrm{J}$ Sports Med. Published Online First: 26 February 2020. doi: 10.1136/bjsports-2019-101916.

7. Corrado D, Pellicia A, Bjornstad HH et al. Cardiovascular pre-participation screening of young competitive athletes for prevention of sudden death: proposal for common European protocol. Consensus statement of the Study Group of Sport Cardiology of the working group of cardiac rehabilitation and exercise physiology and the working group of myocardial and pericardial diseases of the European Society of Cardiology. Eur Heart J. 2005;26(5):516-24.

8. Kay S, Moore BM, Moore L et al. Rugby player's aorta: alarming prevalence of ascending aortic dilatation and effacement in elite rugby players. Heart Lung Circulation. 2020;29:196-201.

9. La Gerche A, Baggish AL, Levine BD et al. Fears of a big bang for rugby players, urgent validation required. Heart Lung Circulation. 2020;29:167-168.

10. Drezner JA, Sharma S, Baggish A et al. International criteria for electrocardiographic interpretation in athletes: Consensus statement. Br J Sports Med. 2017;51(9):704-731. 
11. Lang RM, Badano LP, Mor-Avi V et al. Recommendations for cardiac chamber quantification by echocardiography in adults: an update from the American Society of Echocardiography and the European Association of Cardiovascular Imaging. Eur Heart J Cardiovasc Imaging. 2015;16:233-70.

12. Eligibility and Disqualification Recommendations for Competitive Athletes with Cardiovascular Abnormalities: Preamble, Principles, and General Considerations: A Scientific Statement From the American Heart Association and American College of Cardiology. J Am Coll Cardiol. 2015;66(21):2343-2349.

13. Riding NR, Salah O, Sharma S et al. Do big athletes have big hearts? Impact of extreme anthropometry upon cardiac hypertrophy in professional male athletes. Br J Sports Med. 2012;46:90-7.

14. Chevalier L, Kervio G, Corneloup L et al. Athletes' heart patterns in elite rugby players: effects of training specificities. Arch Cardiovasc Dis. 2013;106(2):72-8.

15. Pellicia A, Di Paolo FM, De Blasiis et al. Prevalence and clinical significance of aortic root dilation in highly trained competitive athletes. Circulation. 2010;122(7):698-706.

16. Iskandar A, Thompson PD. A meta-analysis of aortic root size in elite athletes. Circulation. 2013;127(7):791-8.

17. Schnell F, Riding N, O'Hanlon R et al: The recognition and significance of pathological T-wave inversions in athletes. Circulation. 2015;131(2):165-173.

18. Johnson C, Forsythe L, Somauroo J et al. Cardiac structure and function in elite native Hawaiian and Pacific islander Rugby Football League athletes: an exploratory study. Int J Cardiovasc Imaging. 2018;34(5):725-734.

19. Forsythe L, Somauroo J, George K et al. The right heart of elite senior Rugby Football League athlete. Echocardiography. 2019;36(5):888-895.

20. Oates SA, Forsythe L, Somauroo JD et al. Scaling to produce size-independent indices of echocardiographic derived aortic root dimensions in elite Rugby Football League players. Ultrasound. 2019;27(2):94-100.

21. Uberoi A, Sadik J, Lipinski MJ et al. Association between cardiac dimensions and athlete lineup position: analysis using echocardiography in NCAA football team players. Phys Sportsmed. 2013;41(3):58-66.

22. Stefani L, Galanti G, Toncelli L et al. Bicuspid aortic valve in competitive athletes. Br J Sports Med. 2008;42(1):31-5. 
23. Spataro A, Pellicia A, Rizzo M et al. The natural course of bicuspid aortic valve in athletes. Int J Sports Med. 2008;29(1):81-5.

24. Galanti G, Stefani L, Toncelli L et al. Effects of sports activity in athletes with bicuspid aortic valve and mild aortic regurgitation. Br J Sports Med. 2010;44(4):275-9.

25. D'Andrea A, Cocchia R, Riegler L et al. Aortic stiffness and distensibility in top-level athletes. J Am Soc Echocardiogr. 2012;25:561-7.

26. Pelliccia A, Di Paolo FM, Quattrini FM. Aortic root dilatation in athletic population. Prog Cardiovasc Dis. 2012;54(5):432-7.

27. Gati S, Malhotra A, Sedgwick C et al. Prevalence and progression of aortic root dilatation in highly trained young athletes. Heart. 2019;105(12):920-25.

28. Abuli M, Grazioli G, Sanz de la Garza M et al. Aortic root remodelling in competitive athletes. Eur J Prev Cardiol. 2019:2047487319894882.

29. Gentry JL 3rd, Carruthers D, Joshi PH et al. Ascending aortic dimensions in former National Football League $\begin{array}{lllll}\text { athletes. } & \text { Circ } & \text { Cardiovasc } & \text { Imaging. } & \text { 2017; } \\ \text { aii:e006852. }\end{array}$ 
Table 1. Demographic characteristics of athletes $(n=336)^{*}$

\begin{tabular}{lc}
\hline Age (years) & $24 \pm 5$ \\
Body surface area $\left(\mathrm{m}^{2}\right)$ & $2.25 \pm 0.19$ \\
Height $(\mathrm{cm})$ & $183 \pm 26$ \\
Systolic blood pressure $(\mathrm{mmHg})$ & $114 \pm 12.2$ \\
Ethnicity & \\
Caucasian & $252(75 \%)$ \\
African/Afro-Carribean & $29(8.6 \%)$ \\
Islanders & $55(16.4 \%)$ \\
Position & \\
Forward & $180(54 \%)$ \\
Back & $156(46 \%)$ \\
\hline
\end{tabular}

*Data are expressed as mean \pm SD. 
Table 2. Echographic characteristics of athletes*

\begin{tabular}{lccc}
\hline & All players & Non dilated Aorta & Dilated Aorta \\
Heart rythm (bpm) & $55 \pm 14$ & $54 \pm 13$ & $56 \pm 13$ \\
Aortic sinus of Valsalva & $33.2 \pm 4.0$ & $32.8 \pm 3.4$ & $43.4 \pm 3.2$ \\
diameter (mm) & & & \\
Aortic sinus of Valsalva & $14.9 \pm 3.0$ & $14.8 \pm 2.9$ & $18.5 \pm 1.8$ \\
diameter (mm/m²) & & & \\
Aortic sinus of Valsalva & $17.8 \pm 2.2$ & $17.6 \pm 2.0$ & $22.9 \pm 1.7$ \\
diameter (mm/m) & & & \\
Max-LVWT (mm) & $9.1 \pm 1.5$ & $8.6 \pm 2.1$ & $10.1 \pm 2.5$ \\
LVED (mm) & $56.1 \pm 5.1$ & $55.4 \pm 5.0$ & $56.7 \pm 3.1$ \\
LVM/BSA (g/m $)$ & $93 \pm 23$ & $91 \pm 14$ & $94 \pm 20$ \\
LVFS(\%) & $36 \pm 7$ & $36 \pm 7$ & $37 \pm 6$ \\
LAD $(\mathrm{mm})$ & $32 \pm 7$ & $31 \pm 6$ & $33 \pm 2$ \\
AV Vmax $(\mathrm{m} / \mathrm{s})$ & $1.42 \pm 0.51$ & $1.45 \pm 0.41$ & $1.38 \pm 0.30$ \\
E/A & $1.9 \pm 0.5$ & $2.0 \pm 0.4$ & $1.9 \pm 0.3$ \\
RVOT1 (mm) & $29.2 \pm 6.2$ & $28.8 \pm 4.9$ & $29.4 \pm 5.1$ \\
RVOT2 (mm) & $24.1 \pm 4.7$ & $24.0 \pm 3.7$ & $24.2 \pm 3.1$ \\
RVD1 (mm) & $35.2 \pm 4.7$ & $35.0 \pm 4.7$ & $35.3 \pm 4.3$ \\
RVD2 (mm) & $26.0 \pm 5.6$ & $26.1 \pm 3.2$ & $24.9 \pm 6.7$ \\
RVD3 (mm) & $71.0 \pm 8.2$ & $70.1 \pm 7.2$ & $72.3 \pm 7.3$ \\
\hline
\end{tabular}

*Data are expressed as mean \pm SD.

Aorta $\mathrm{mm} / \mathrm{m}$, height indexation; Max-LVWT, maximal left ventricular wall thickness in end diastole; LVED, left ventricular end-diastolic diameter; LVM/BSA, left ventricular mass/body surface area; LVFS, left ventricular fractional shortening; LAD, left atrial diameter. AV Vmax, continuous wave aortic flow velocity; E/A, ratio of early diastolic mitral valve peak inflow velocity to late diastolic mitral valve inflow velocity; RVOT, right ventricular outflow tract diameter in parasternal short-axis view at atrioventricular level (RVOT1), pulmonary valve annulus (RVOT2); RVD, right ventricular diameter in apical-4-chamber view at basal line (RVD1), middle (RVD2) and longitudinal measure (RVD3). 
Table 3. Characteristics of abnormalities observed on ECG and/or ECHO

Abnormal 6 players $\quad$ Negative T 2 players with abnormal TTE

electrocardiogram

waves

$(\mathrm{n}=6)$

Abnormal

13 aortic dilation with tricuspid aortic valve

echocardiography

1 aortic dilation with bicuspid aortic valve and regurgitation

$(\mathrm{n}=21)$

\begin{tabular}{l}
\hline 1 bicuspid aortic valve without complication \\
\hline 1 isolated moderate aortic regurgitation \\
\hline 1 mitro-aortic valvulopathy \\
\hline 1 minor HCM \\
\hline 2 LVED $>65 \mathrm{~mm}$ \\
\hline
\end{tabular}

1 abnormal origin of coronary artery

TTE: transthoracic echocardiography; HCM: hypertrophic cardiomyopathy; LVED: left ventricle end diastolic diameter 
Table 4. Characteristics of players with dilated aorta

\begin{tabular}{|c|c|c|c|c|c|c|c|c|c|}
\hline $\begin{array}{l}\text { Age } \\
\text { (years) }\end{array}$ & $\begin{array}{l}\text { Height } \\
\text { (cm) }\end{array}$ & $\begin{array}{l}\text { Weight } \\
(\mathrm{kg})\end{array}$ & $\mathrm{BSA}\left(\mathrm{kg} / \mathrm{m}^{2}\right)$ & Ethnicity & Position & $\begin{array}{l}\text { Aortic sinus } \\
\text { of Valsalva } \\
\text { diameter } \\
\text { (mm) }\end{array}$ & $\begin{array}{l}\text { Z- } \\
\text { Score }\end{array}$ & $\begin{array}{l}\text { Aortic sinus } \\
\text { of Valsalva } \\
\text { diameter } \\
\left(\mathrm{mm} / \mathrm{m}^{2}\right)\end{array}$ & $\begin{array}{l}\text { Aortic sinus of } \\
\text { Valsalva diameter } \\
(\mathrm{mm} / \mathrm{m})\end{array}$ \\
\hline $\begin{array}{ll}\text { Player } 20 \\
1\end{array}$ & 192 & 110 & 2.40 & $\begin{array}{l}\text { African/Afro- } \\
\text { Carribean }\end{array}$ & Forward & 48 & 5.20 & 20 & 25 \\
\hline $\begin{array}{ll}\text { Player } 30 \\
2\end{array}$ & 176 & 95 & 2.11 & Islander & Back & 44 & 3.84 & 21 & 25 \\
\hline $\begin{array}{l}\text { Player } 26 \\
3\end{array}$ & 195 & 128 & 2.58 & Caucasian & Forward & 41 & 1.99 & 16 & 21 \\
\hline Player 26 & 192 & 109 & 2.39 & Caucasian & Forward & 41 & 2.33 & 17 & 21 \\
\hline $\begin{array}{l}\text { Player } 21 \\
5\end{array}$ & 191 & 106 & 2.38 & Islander & Forward & 42 & 2.90 & 18 & 22 \\
\hline $\begin{array}{l}\text { Player } 24 \\
6\end{array}$ & 183 & 94 & 2.16 & Caucasian & Back & 42 & 3.19 & 19 & 23 \\
\hline $\begin{array}{l}\text { Player } 20 \\
7\end{array}$ & 184 & 88 & 2.11 & Caucasian & Back & 42 & 3.41 & 20 & 23 \\
\hline $\begin{array}{l}\text { Player } 28 \\
8\end{array}$ & 194 & 108 & 2.40 & Caucasian & Forward & 49 & 5.33 & 21 & 25 \\
\hline $\begin{array}{l}\text { Player } 29 \\
9\end{array}$ & 192 & 114 & 2.43 & Caucasian & Forward & 41 & 2.16 & 17 & 21 \\
\hline $\begin{array}{l}\text { Player } 26 \\
10\end{array}$ & 186 & 120 & 2.43 & Caucasian & Forward & 41 & 2.26 & 17 & 22 \\
\hline $\begin{array}{l}\text { Player } 25 \\
11\end{array}$ & 182 & 110 & 2.30 & $\begin{array}{l}\text { African/Afro- } \\
\text { Carribean }\end{array}$ & Forward & 44 & 3.67 & 19 & 24 \\
\hline $\begin{array}{l}\text { Player } 23 \\
12\end{array}$ & 180 & 91 & 2.11 & Caucasian & Back & 41 & 2.93 & 19 & 23 \\
\hline $\begin{array}{l}\text { Player } 35 \\
13\end{array}$ & 200 & 115 & 2.51 & Islander & Forward & 50 & 5.26 & 20 & 25 \\
\hline $\begin{array}{l}\text { Player } 28 \\
14\end{array}$ & 204 & 121 & 2.61 & Islander & Forward & 41 & 1.87 & 16 & 20 \\
\hline
\end{tabular}

BSA, body surface area 


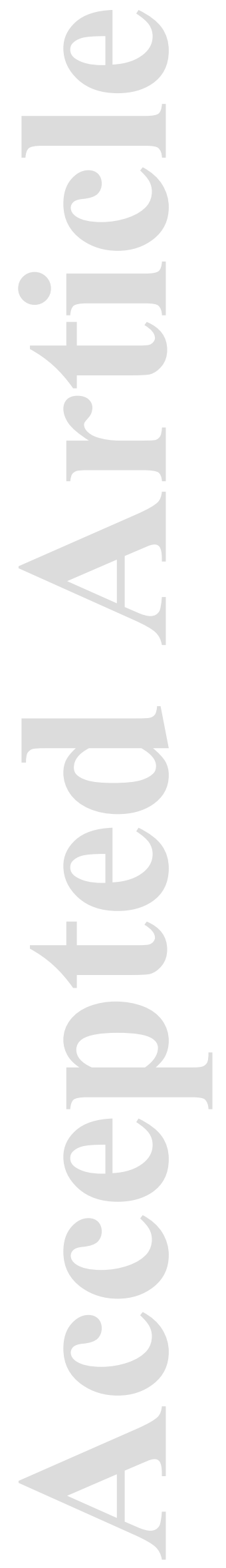


Table 5. Aortic sinus of Valsalva diameters* observed in whole population studied in relation with players' characteristics (position on field, age and ethnicity)

\begin{tabular}{|c|c|c|c|c|c|c|c|c|c|c|}
\hline$(2)$ & Position & & & Age & & & Ethnic group & & & \\
\hline$\sqrt{2+1}$ & Forward & Back & $\mathrm{p}$ & $18-25$ years & $>25$ years & $\mathrm{p}$ & $\begin{array}{l}\text { Pacific } \\
\text { Islanders (a) }\end{array}$ & $\begin{array}{l}\text { Afro-Caribbeans } \\
\text { (b) }\end{array}$ & Caucasians (c) & $\mathrm{p}$ \\
\hline $\begin{array}{l}\text { Absolute } \\
\text { diameter } \\
(\mathrm{mm})\end{array}$ & 34 [24-50] & $32[25-44]$ & 0.01 & $32[23-48]$ & $33.5[24-50]$ & 0.02 & $34[25-50]$ & $32[27-48]$ & 33 [23-49] & $\begin{array}{l}\text { (a) vs (b): } p=0.033 \\
\text { (a) vs (c): } p=0.0015 \\
\text { (b) vs (c): } p=N S\end{array}$ \\
\hline $\begin{array}{l}\text { Indexed to } \\
\text { BSA } \\
\text { diameter } \\
\left(\mathrm{mm} / \mathrm{m}^{2}\right)\end{array}$ & $14[10-21]$ & 15 [11-21] & 0.02 & $14.7[10-20]$ & $14.9[10.1-20.9]$ & 0.67 & $15[12.2-21]$ & 14.8 [11-19.9] & 14.8 [10-20.9] & $\begin{array}{l}\text { (a) vs (b): } p=0.0331 \\
\text { (a) vs (c): } p=0.015 \\
\text { (b) vs (c): } p=N S\end{array}$ \\
\hline $\begin{array}{l}\text { Indexed to } \\
\text { height } \\
\text { diameter } \\
(\mathrm{mm} / \mathrm{m})\end{array}$ & 18 [12-25] & 18 [12-25] & 0.14 & 17.4 [12.2-25] & $18[12.2-27.5]$ & 0.01 & 18.5 [14-25] & 17.4 [14.8-25] & $17.6[12.2-25.3]$ & $\begin{array}{l}\text { (a) vs (b): } p=0.045 \\
\text { (a) vs (c): } p=0.0093 \\
\text { (b) vs (c): } p=N S\end{array}$ \\
\hline
\end{tabular}

*Data are expressed as median [range]. BSA, body surface area, Aorta $\mathrm{mm} / \mathrm{m}$, height indexation 